\title{
Recognition of facial emotional expressions and its correlation with cognitive abilities in children with Down syndrome
}

\author{
Carla C. V. P. de Santana, Wânia C. de Souza, and M. Angela G. Feitosa \\ Universidade de Brasília, Brasília, DF, Brazil
}

\begin{abstract}
Down syndrome (DS) is one of the most common chromosomal abnormalities. Delays in cognitive development are found in the first years of life. As years pass, it may turn into intellectual deficiencies that unfold into several aspects, including difficulty recognizing emotional facial expressions. The present study investigated the recognition of six universal facial emotional expressions in a population of children aged 6-11 years who were divided into two groups: DS group and typically developing children (TDC) group. We used the Perception Test of Facial Emotional Expressions (Teste de Percepção de Emoções Faciais; TEPEF) and Wechsler Intelligence Scale for Children (WISC-III) and found that children with DS presented alterations in the recognition of expressions of disgust, surprise, and fear, whereas the recognition of happiness, sadness, and anger was maintained at a level comparable to the TDC group. Participants with DS presented significant positive correlations between sadness and Picture completion, Mazes, Arithmetic, Vocabulary, Digits, Verbal IQ, Verbal Comprehension Index, and Working Memory Index. All other facial expressions showed significant negative correlations with the Intelligence Quotient and WISC-III factorial index subtests. Absence of correlations was found among the TEPEF's six facial expressions and Information, Coding, Symbols, and Working Memory Index. The contribution of this study is related to understanding the characteristics of the recognition of facial emotions in children with DS, an important component of social relationships with their peers, schools, and families. Keywords: Down Syndrome, recognition of facial expressions, visual perception.
\end{abstract}

Received 03 October 2013; received in revised form 07 May 2014; accepted 29 May 2014. Available online 27 June 2014.

\section{Introduction}

Down syndrome (DS) is a genetic condition that was first described by John Langdon H. Down (Down, 1886) and associated with chromosome 21 trisomy by Lejeune, Gautier, and Turpin (1959), and has since been widely studied. This syndrome is related to a delay in development that begins in the first years of life, leading to intellectual deficiency. Other phenotypic characteristics include brachycephaly, brachydactyly, an epicanthal fold, hypotonia, lax ligaments, a short stature, and an open mouth (Roizen \& Patterson, 2003). Throughout psychomotor development, the cognitive functions that may undergo further changes include auditory perception, attention, cognition, motivation, and language (Tristão \& Feitosa, 1998, 2002). A timeline of a general cognitive profile of individuals with DS shows that learning delays in infancy $(0-4$ years) are common at ages 0-2 and accelerate at ages 2-4.

Carla Cristina Vasconcelos Pena de Santana, Wânia Cristina de Souza, and Maria Angela Guimarães Feitosa, Universidade de Brasília. Correspondence regarding this article should be directed to: Wânia Cristina de Souza, Universidade de Brasília, Instituto de Psicologia, Departamento de Processos Psicológicos Básicos, Brasília - DF- Brazil, 70.910-900. E-mail:wcdeep@gmail.com
In childhood (4-12 years), selective deficits are found in verbal short-term memory. In adolescence (13-18 years), deficits are found in verbal working memory and delayed recall. In adulthood, $50 \%$ of the population over the age of 50 have behavioral symptoms of dementia (Chapman \& Hesketh, 2000).

Studies on the morphology of the central nervous system in people with DS have shown reduced brainstem size (Benda, 1971), abnormalities in the development of the frontal lobes and hippocampus (Raz et al., 1995), defective development of the frontal lobes, and diminished size of the limbic area (Jernigan, Bellugi, Sowell, Doherty, \& Hesselink, 1993). All of these areas are involved in the functioning of the amygdala, the cerebral structure that is responsible for processing and regulating emotional information in the human brain.

Analyzing the relationship between emotion and cognition in visual information processing, Pessoa (2008) used functional magnetic resonance imaging (fMRI) and found that the affective component of visual information is reflected at multiple stages of processing, from early visual areas (including V1) to prefrontal sites. Thus, cognitive and emotional components cannot be separated. For example, visual cortical responses that reflect an item's significance result from simultaneous top-down modulation by frontoparietal attentional regions and emotional modulation in the amygdala. 
Therefore, the item's impact on behavior is both cognitive and emotional.

Hippolyte, Barisnikov, Van der Linden, and Detraux (2009) suggested that people with DS undergo changes in the ability to recognize facial expressions of emotion and, subsequently, the ability to understand emotional states. These abilities are essential to the development and maintenance of appropriate social relations. Facial expressions allow the perception of crucial information that characterizes mental states and attributes.

The perception of faces is one of the most developed human abilities. Face recognition, facial emotional expression, and the detection of a fixed gaze direction play crucial roles in non-verbal communication. The face is important in the process of identifying and recognizing peers and can provide different kinds of information, such as familiarity or the nature of the emotion that is being felt (De Souza, Feitosa, Eifuku, Tamura, \& Ono, 2008).

Likewise, the ability to distinguish faces among people and the processing of faces and voices are also involved in the development of nonverbal communication (Argyle, 1983). Non-verbal communication is mostly used to indicate emotional states and attitudes. It is also used to coordinate conversation, and is a precursor of expressive language. Studies suggest that the delay in language development presented by children with DS can be associated with a premature disorder of non-verbal communication ability (Mundy, Kasari, Sigman, \& Ruskin, 1995; Mundy, Sigman, Kasari, \& Yirmiya, 1988; Smith $\&$ von Tetzchner, 1986). Another fact that must be considered is the presence of facial hypotony in people with DS because it interferes directly with their ability to precisely express emotions.

Smith and Dodson (1996) investigated adults with DS and their ability to facially express emotions when exposed to videos with happy, sad, and neutral content. Regardless of the kind of emotion presented (i.e., positive, negative, or neutral), participants had difficulty reproducing through facial muscles the same expressions to which they were exposed (i.e., negative or neutral). The expressions displayed were exaggerated and even not compatible with the image presented. Despite the subjects' good results with positive facial expressions, the authors concluded that an increase in non-emotional or irrelevant facial expressions could potentially interfere with the ability of others to accurately interpret their emotionally or socially relevant facial expressions.

In a study of the ability of teenagers with DS to recognize facial expressions of emotion, Williams, Wishart, Pitcairn, and Willis (2005) evaluated 126 participants, of which 34 had DS (11 male, 23 female; 7.67-17.67 years old), 53 had nonspecific intellectual disabilities (29 male, 24 female; 6-17.42 years old), and 39 were typically developing children ( 22 male, 17 female; 2.75-5.58 years old). Cognitive ability was assessed using the Wechsler Preschool and Primary
Scales of Intelligence (WPPSI-R; Wechsler, 1990) and Wechsler Intelligence Scale for Children (WISC-III; Wechsler, 1992). To match participants with regard to performance criteria, the Benton Facial Recognition Test was administered (Benton, Sivan, Hamsher, Varney, \& Spreen, 1983). For the experimental task, the Facial Affect Slides of Ekman and Friesen (1976) were used. The data suggested that teenagers with DS presented performance similar to younger children who had no developmental alterations, suggesting that they had the same response pattern.

Numerous studies have focused on the processing of faces in children with DS. Most of the studies addessed the recognition of facial emotional features (Cebula, Moore, \& Wishart, 2010; Williams et al., 2005; Wishart \& Pitcairn, 2000; Wishart, Cebula, Willis, \& Pitcairn, 2007) and compared children to DS and children with other kinds of intellectual disabilities but who had equivalent cognitive and linguistic status in a very heterogeneous age group, including preschoolers and teenagers. Williams et al. (2005) compared a DS group (7.6-17.6 years old) with children with nonspecific intellectual disabilities (6-17.4 years old) and typically developing children (2.7-5.5 years old). Wishart et al. (2007) compared an intellectual disability group that included DS children (6-18 years old) with typically developing children (2.7-7.5 years old). For many children with DS, relative to their peers, comprehending their emotions and intentions is as complex as any ability of development (Cebula et al., 2010).

The present study had two objectives. The first was to verify the existence of impairment in the recognition of emotional facial expressions in children with DS. The hypothesis was that inferior performance in the recognition of facial expressions would be found in the children with DS, when compared with typically developing children. To test this hypothesis, we used the Perception of Facial Emotional Expressions Test (Teste de Percepção de Emoções Faciais; TEPEF), which was developed and applied by Ladislau (2010) in her work with elderly people with Alzheimer's disease. The second objective was to identify a pattern of cognitive characteristics in children with DS. Our hypothesis was that we would find inferior performance in perceptual motor tasks in the DS group, when compared with typically developing children. We evaluated cognitive performance in the DS group using the WISC-III and compared their results with typically developing children.

\section{Methods}

\section{Participants}

Participants were 60 children, 6-11 years of age (30 children in the DS group with a confirmed diagnosis of the DS karyotype and 30 children in the typically developing children [TDC] group without DS). In the DS group, 13 participants were female and 17 were male. In the TDC group, 16 participants were female 
and 14 were male (Table 1). DS participants were invited from programs of inclusion in regular classes at regular elementary schools, and the TDC participants attended the same schools (Table 2).

Table 1. Gender composition of the typically developing children (TDC) and Down syndrome (DS) groups.

\begin{tabular}{llll}
\hline TDC group & \multicolumn{3}{c}{ DS group } \\
\hline Male & Female & Male & Female \\
$47 \%$ & $53 \%$ & $57 \%$ & $43 \%$ \\
\hline
\end{tabular}

Table 2. Age and years of education in the typically developing children (TDC) and Down syndrome (DS) groups.

\begin{tabular}{lcccc}
\hline $\begin{array}{l}\text { Demographic } \\
\text { characteristic }\end{array}$ & \multicolumn{2}{r}{ TDC group } & \multicolumn{2}{c}{ DS group } \\
& Mean & SD & Mean & SD \\
& 8.17 & 1.72 & 8.83 & 1.84 \\
Age (years) & 5.36 & 1.70 & 6.03 & 1.83 \\
Education (years) & & & & \\
\hline
\end{tabular}

All of participants underwent assessment in a private environment. In compliance with school requirements to preserve the privacy of the children and their families, no videotaping or photographing was done.

\section{Instruments}

Test of Perception of Facial Emotional Expressions (TEPEF). Used for the assessment of facial emotional perception, this software was developed by Ladislau (2010) in a former study on the emotional perception of faces in elderly people with Alzheimer's disease. The data showed that healthy elderly individuals presented lower accuracy rates: $80.30 \%$ Happiness, $36.36 \%$ Sadness, $12.12 \%$ Disgust, 9.09\% Surprise, 6.06\% Fear, and $16.67 \%$ Anger. TEPEF contains 126 pictures of 46 male and female volunteers (undergraduate students of Performing Arts) who exhibit, only by facial expressions, the six universal basic emotions: happiness, sadness, anger, disgust, fear, and surprise. Thirty-five images were selected for this study: six sadness, six happiness, six anger, six fear, six surprise, and five disgust (the expression of disgust had only five photographs because these were the ones that better fitted the criteria of quality and standardization). The photographs consisted of both male and female faces. For each emotion, the different pictures were of different individuals. We did not control for the repetition of individuals between different emotions. Each picture was centered on the computer screen, and icons were displayed below the pictures with the names of the six facial emotional expressions, from left to right: happiness, sadness, disgust, surprise, fear, and anger, with an additional option of "I don't know." Each picture was presented twice to confirm the selected option and avoid that the choice was made by chance. Therefore, the participant would respond to two random presentations of each picture to confirm the answer. The sequence of presentation of the pictures was programed to be semi-randomized to prevent the same emotion from being presented twice consecutively, such that an expression of disgust, for example, could not be presented immediately after another expression of disgust, according to the presentation guidelines established by Ladislau. TEPEF does not allow an analysis of each view. It provides only the number of trials and errors through the double-hit criterion established by its author.

Wechsler Intelligence Scale for Children, 3rd edition (WISC-III). This scale was used to assess visuospatial and verbal ability. It is a cognitive battery composed of various subtests that analyze these abilities, and it has been standardized and validated for the Brazilian population (Wechsler, 2002). Therefore, obtaining data on general and specific cognitive functioning was possible.

\section{Environment}

The assessment environment was adjusted to each participant's daily routine and included the participant's house, his/her school, and a private office. In all locations, a table with three chairs of the same height as the child's chair were used. Natural light and basic patterns of the control of environmental sound were maintained.

\section{Procedures}

In the first stage, executed in a single session, the participant and his/her responsible guardian read, together with the researcher, the Term of Free and Informed Consent and signed it after proper explanations. The demographic questionnaire was applied, and a pretest was used to assess the child's comprehension of the given commands and the child's way of naming each assessed expression.

The second stage was the application of WISCIII (12 standard subtests for the Brazilian population) and TEPEF. The data were individually collected in the presence of the responsible guardian. The same person applied all tests to every child. Time needed for this stage varied from two to five meetings, each lasting an average of $1.5 \mathrm{~h}$. The application of the WISC-III had to be divided because of the behavioral characteristics of the DS participants, who often present low tolerance to directed activities and reduced sustained attention. The application of the TEPEF lasted approximately $15 \mathrm{~min}$ and was performed in a single session.

The third stage was dedicated to providing feedback to the responsible guardians about the participants' results.

\section{Statistical analysis}

The statistical analysis was performed using SPSS 16 software (Statistical Package for the Social Sciences). The data were analyzed using the nonparametric Mann- 
Whitney test to compare the rates of correct recognition between the two independent groups. The parametric Pearson test was used to examine the correlations between the rates of correct recognition and scores on each subtest (two quantitative variables).

\section{Results}

We verified the normality of the data distribution using the Kolmogorov-Smirnov test. Because all $p$ values were less than .05 , normality in the proportion of correct answers was not observed (Table 3).

For the facial expressions of happiness, sadness, and anger, we found high levels of correct recognition in the TDC group (98, 98, and 97\%, respectively) and DS group (98, 94, and $86 \%$, respectively; Table 4), a pattern of results that is consistent with the literature (Darwin, 1872; Ekman, 1972; Ekman et al., 1987; Matsumoto \& Hwang, 2011). For the facial expressions of disgust, surprise, and fear, a significant difference in recognition was found between the TDC group $(81,51$, and $69 \%$, respectively) and DS group (37, 8, and $40 \%$, respectively; Table 4).

Table 3. Normality of the data distribution in the typically developing children (TDC) and Down syndrome (DS) groups.

\begin{tabular}{lcccccc}
\hline & \multicolumn{5}{c}{ Kolmogorov-Smirnov $^{\mathrm{a}}$} \\
\cline { 2 - 7 } expression & \multicolumn{3}{c}{ TDC group } & \multicolumn{3}{c}{ DS group } \\
\cline { 2 - 7 } & Statistic & df & Sig. & Statistic & df & Sig. \\
\hline Happiness & .528 & 30 & .000 & .531 & 30 & .000 \\
Sadness & .531 & 30 & .000 & .459 & 30 & .000 \\
Disgust & .248 & 30 & .000 & .165 & 30 & .036 \\
Surprise & .161 & 30 & .045 & .395 & 30 & .000 \\
Fear & .216 & 30 & .001 & .198 & 30 & .004 \\
Anger & .503 & 30 & .000 & .414 & 30 & .000 \\
\hline Total & .184 & 30 & .011 & .164 & 30 & .038 \\
\hline
\end{tabular}

${ }^{a}$ Lilliefors significance correction

Pearson's correlation was used to compare TEPEF's facial emotional expressions and WISC-III Intelligence Quotient (IQ) and factorial index subtests. Both instruments were used to evaluate the children in the TDC group (Table 5) and DS group (Table 6). For the participants in the TDC group (Table 5), facial expressions of disgust and surprise had significant positive correlations with the cognitive tests and factorial indices: between disgust and Symbols $(r=$ .440), between disgust and Processing Speed Index (PSI; $r=.388)$, between surprise and Arithmetic $(r=$ .434 ), and between surprise and Working Memory Index (WMI; $r=.451$ ). For all other facial expressions (happiness, sadness, fear, and anger), significant negative correlations were observed with the WISCIII tests (Table 5). No correlation was found among the TEPEF's six facial expressions (happiness, sadness, disgust, surprise, fear, and anger) and the following WISC-III subtests: Picture completion, Information, Coding, Picture arrangement, and Block design.

Table 4. Accuracy rate in the perception of facial emotional expressions using the TEPEF in the typically developing children (TDC) and Down syndrome (DS) groups.

\begin{tabular}{lcccc}
\hline \multirow{2}{*}{ Facial expression } & \multicolumn{2}{c}{ TDC group } & \multicolumn{2}{c}{ DS group } \\
\cline { 2 - 5 } & Mean (\%) & SD & Mean (\%) & SD \\
\hline Happiness & 98 & .06 & 98 & .08 \\
Sadness & 98 & .08 & 94 & .12 \\
Disgust & 81 & .18 & $37^{*}$ & .29 \\
Surprise & 51 & .33 & $8^{*}$ & .11 \\
Fear & 69 & .3 & $40^{*}$ & .32 \\
Anger & 97 & .08 & 86 & .3 \\
\hline
\end{tabular}

$* p<.01$ (Mann-Whitney test).

For the participants with DS (Table 6), the facial expression of sadness presented significant positive correlations with the following cognitive tests, IQ, and factorial indices: Picture completion $(r=.431)$, Mazes $(r=.496)$, Arithmetic $(r=.382)$, Vocabulary $(r$ $=.392)$, Digits $(r=.419)$, Verbal IQ $(r=.493)$, Verbal Comprehension Index (VCI; $r=.440$ ), and WMI $(r=.507)$. All other facial expressions (happiness, disgust, surprise, fear, and anger) showed significant negative correlations with the subtests, IQ, and WISCIII factorial indices. Considering specifically the expression of anger, the negative correlations were statistically significant, from moderate to high, with several WISC-III parameters: Picture arrangement $(r=$ -.439), Arithmetic $(r=-.414)$, Block design $(r=-.635)$, Vocabulary $(r=-.636)$, Object assembly $(r=-.411)$, Comprehension $(r=-.674)$, Verbal IQ $(r=-.585)$, Execution IQ $(r=-.550)$, Total IQ $(r=-.620)$, VCI $(r=$ -.632), and Perceptual Reasoning Index (PRI; $r=-.608$ ). Absence of correlation was found among the TEPEF's six facial expressions (happiness, sadness, disgust, surprise, fear, and anger) and the following subtests and factorial indices of the WISC-III: Information, Coding, Symbols, and WMI.

\section{Discussion}

Studies have been performed to comprehend the processing of faces in children with DS, most of them related to emotional recognition (Cebula et al., 2010; Hippolyte et al., 2009; Williams et al., 2005; Wishart et al., 2007; Wishart \& Pitcairn, 2000). In the present study, we investigated the perception of facial emotional expressions in a group of children with DS and a 
Table 5. Pearson correlations between subtests, Intelligence Quotients, and index scores of the WISC-III in the typically developing children group.

\begin{tabular}{|c|c|c|c|c|c|c|}
\hline \multirow{2}{*}{ WISC-III } & \multicolumn{6}{|c|}{ Facial expression } \\
\hline & Happiness & Sadness & Disgust & Surprise & Fear & Anger \\
\hline Picture completion & -.294 & .018 & .128 & .303 & -.284 & -.288 \\
\hline Information & -.202 & -.255 & .09 & -.038 & -.083 & -.271 \\
\hline Coding & -.258 & -.105 & .105 & .141 & -.195 & -.314 \\
\hline Mazes & -.19 & $-.712^{\star *}$ & .114 & .161 & -.278 & -.101 \\
\hline Picture arrangement & -.064 & .167 & -.018 & .068 & -.32 & -.182 \\
\hline Arithmetic & $-.377^{\star}$ & $-.444^{* *}$ & .067 & $.434^{*}$ & -.149 & $-.379^{*}$ \\
\hline Block design & -.156 & -.118 & .21 & .35 & -.27 & -.236 \\
\hline Vocabulary & -.227 & -.29 & .063 & .104 & -.252 & $-.374^{*}$ \\
\hline Object assembly & -.127 & -.096 & -.036 & .108 & $-.477^{* *}$ & -.247 \\
\hline Comprehension & $-.440^{*}$ & -.153 & .152 & .209 & -.02 & $-.383^{*}$ \\
\hline Symbols & -.152 & $-.448^{*}$ & $.440^{*}$ & .346 & $-.456^{*}$ & -.033 \\
\hline Digits & $-.450^{*}$ & .207 & .137 & .293 & .065 & -.108 \\
\hline Verbal IQ & -.352 & $-.448^{\star}$ & .164 & .206 & -.204 & $-.388^{*}$ \\
\hline Execution IQ & -.171 & -.015 & .161 & .233 & $-.415^{\star}$ & -.27 \\
\hline Total IQ & -.31 & -.298 & .188 & .252 & -.34 & $-.375^{*}$ \\
\hline VCI & -.305 & $-.407^{\star}$ & .12 & .133 & -.177 & -.321 \\
\hline PRI & -.169 & -.021 & -.002 & .31 & $-.467^{* *}$ & -.313 \\
\hline WMI & $-.482^{\star *}$ & -.215 & .108 & $.451^{*}$ & -.076 & -.328 \\
\hline PSI & -.259 & $-.369^{*}$ & $.388^{*}$ & .344 & $-.436^{*}$ & -.208 \\
\hline
\end{tabular}

${ }^{*} p<.05,{ }^{* *} p<.01$

group of children with regular development using the TEPEF. The results showed significant differences in the perception of expressions of disgust, surprise, and fear (Table 4), in which the children with DS had lower accuracy than the children in the TDC group.

The reduced recognition of the expression of fear by individuals with DS is consistent with previous reports by Kasari, Freeman, and Hughes (2001), Porter, Coltheart, and Langdon (2007), Williams et al. (2005), Wishart \& Pitcairn (2000), and Wishart et al. (2007).

The difficulties presented by individuals with DS in the recognition of facial expressions of surprise were also described by Wishart and Pitcarirn (2000). In a study of patients with Parkinson's disease, Clark, Neargarde, and Cronin-Golomb (2008) analyzed the ambiguous aspect of the expression of surprise, which can be linked to either a positive situation (and therefore misinterpreted as happiness) or a negative situation (and therefore misinterpreted as fear). Hippolyte, Barisnikov, and Van der Linden (2008) found evidence of difficulty recognizing neutral and surprise emotional expressions among adults with DS.
The high percentage of success in recognizing the expression of happiness (98\%) in both the TDC group and DS group (Table 4) follows the universal patterns described in the studies by Darwin (1809-1882), Ekman (1972, 1993), and, more recently, Hippolyte et al. (2009).

The percentage of success in recognizing the expression of sadness in the DS group (94\%; Table 4) contrasts with the findings of Hippolyte et al. (2009), in which difficulty recognizing the emotional expression of sadness was found in adults with DS (average age, 34.3 years).

Considering the expression of negative emotions, we found that children with DS presented a higher percentage of correct recognition of negative emotions compared to the TDC group. Few studies have analyzed the discrimination of emotional valence perceived only through facial expressions in people with DS. In a study of affective facilitation, Martínez and Ramírez (2005) investigated people with DS (18-25 years old) and required them to recognize emotional faces with short Stimulus Onset Asynchrony (300 ms and $2.000 \mathrm{~ms}$ ). 
Table 6. Pearson correlations between subtests, Intelligence Quotients, and index scores of the WISC-III in the Down syndrome group.

\begin{tabular}{|c|c|c|c|c|c|c|}
\hline \multirow{2}{*}{ WISC-III } & \multicolumn{6}{|c|}{ Facial expression } \\
\hline & Happiness & Sadness & Disgust & Surprise & Fear & Anger \\
\hline Picture completion & -.091 & $.431^{*}$ & -.14 & -.29 & -.105 & -.343 \\
\hline Information & -.169 & .198 & -.178 & -.343 & -.155 & -.199 \\
\hline Coding & .043 & .302 & .089 & .03 & .132 & .023 \\
\hline Mazes & .245 & $.496^{* *}$ & .137 & .117 & .324 & -.154 \\
\hline Picture arrangement & -.282 & .048 & $-.368^{*}$ & $-.555^{\star *}$ & $-.439^{*}$ & $-.439^{*}$ \\
\hline Arithmetic & -.09 & $.382^{\star}$ & -.282 & -.34 & -.32 & $-.414^{*}$ \\
\hline Block design & $-.489^{* *}$ & -.145 & $-.555^{\star *}$ & $-.562^{\star *}$ & $-.593^{\star \star}$ & $-.635^{\star x}$ \\
\hline Vocabulary & $.435^{\star}$ & $.392^{\star}$ & -.135 & -.15 & -.2 & $-.636^{\star *}$ \\
\hline Object assembly & -.147 & .033 & -.224 & -.14 & -.171 & $-.411^{*}$ \\
\hline Comprehension & .105 & .158 & $-.417^{\star}$ & .046 & -.321 & $-.674^{* *}$ \\
\hline Symbols & -.307 & .093 & -.153 & .045 & -.053 & -.18 \\
\hline Digits & .094 & $.419^{*}$ & .038 & .357 & .184 & -.113 \\
\hline Verbal IQ & .164 & $.493^{\star *}$ & -.237 & -.205 & -.183 & $-.585^{\star \star}$ \\
\hline Execution IQ & -.301 & .162 & $-.367^{\star}$ & $-.464^{\star *}$ & $-.369^{*}$ & $-.550^{\star \star}$ \\
\hline Total IQ & -.078 & .359 & -.342 & $-.371^{*}$ & -.319 & $-.620^{* *}$ \\
\hline VCI & .203 & $.440^{*}$ & -.237 & -.131 & -.152 & $-.632^{\star *}$ \\
\hline PRI & -.357 & .097 & $-.451^{\star}$ & $-.536^{\star *}$ & $-.461^{*}$ & $-.608^{* x}$ \\
\hline WMI & -.036 & $.507^{\star *}$ & -.179 & -.025 & -.109 & -.351 \\
\hline PSI & -.148 & .222 & -.042 & .06 & .055 & -.095 \\
\hline
\end{tabular}

$* p<.05, * * p<.01$

Subjects with DS presented more difficulty with negative emotions, and their response latency was significantly longer than that of the participants in the TDC group.

The comparative analysis of the correlation between the perception of facial emotional expression and cognitive ability in the TDC group and DS group revealed some similarities. For both groups, no significant correlations were observed between any of the TEPEF's six facial expressions (happiness, sadness, disgust, surprise, fear, and anger) and two of the WISCIII subtests: Information and Coding (Tables 5 and 6).

Considering the subtests Picture arrangement and Block design, no correlation was found with any facial expression in the TDC group, whereas the participants in the DS group presented moderate negative correlations. The Picture arrangement subtest was significantly correlated with four of the six expressions: disgust, surprise, fear, and anger. The Block design subtest was significantly correlated with five of the six expressions: happiness, disgust, surprise, fear, and anger (Table 5). The Block design task assesses organizational ability, and visuospatial processing ability to mentally decompose a model in order to reproduce it, and it is a non-verbal task for problem solving (Simões, 2002). To perform this activity, coordination, psychomotor agility, visual-constructive abilities, and visuospatial aptitude are necessary. Picture arrangement demands good perceptual analysis ability, concept formation, and the ability to think about visually presented material (Lezak, Howieson, \& Loring, 2004).

Despite the importance of the abilities evaluated in the present study for the recognition of facial emotions, 
Table 7. Mean, standard deviation (SD), and coefficient of variation (CV) on subtests of the WISC-III in the typically developing children (TDC) and Down syndrome (DS) groups.

\begin{tabular}{|c|c|c|c|c|c|c|}
\hline \multirow{2}{*}{ WISC-III } & \multicolumn{3}{|c|}{ TDC group } & \multicolumn{3}{|c|}{ DS group } \\
\hline & Mean & SD & $\mathrm{CV}$ & Mean & SD & CV \\
\hline Picture completion & 11.1 & 1.4 & 12.8 & 5.6 & 1.2 & 22.0 \\
\hline Information & 10.0 & 1.7 & 16.8 & 5.4 & 1.0 & 18.0 \\
\hline Coding & 10.9 & 1.9 & 17.3 & 4.8 & .8 & 16.8 \\
\hline Mazes & 9.6 & 2.0 & 20.5 & 6.0 & 1.1 & 17.5 \\
\hline Picture arrangement & 10.4 & 1.6 & 15.3 & 5.7 & 1.2 & 21.4 \\
\hline Arithmetic & 10.6 & 2.2 & 20.4 & 3.9 & 1.3 & 34.5 \\
\hline Block design & 10.8 & 1.2 & 10.7 & 5.9 & 1.4 & 24.2 \\
\hline Vocabulary & 10.2 & 2.2 & 21.4 & 4.8 & 1.1 & 22.2 \\
\hline Object assembly & 10.9 & 2.0 & 18.0 & 6.2 & .9 & 14.2 \\
\hline Comprehension & 11.2 & 1.9 & 17.0 & 6.1 & 1.1 & 17.4 \\
\hline Symbols & 11.6 & 2.3 & 19.9 & 5.4 & .8 & 15.1 \\
\hline Digits & 10.5 & 1.4 & 13.4 & 4.8 & 1.3 & 26.5 \\
\hline Verbal IQ & 101.5 & 10.4 & 10.2 & 70.0 & 4.7 & 6.7 \\
\hline Execution IQ & 106.5 & 9.0 & 8.5 & 69.8 & 5.5 & 7.9 \\
\hline Total IQ & 103.9 & 9.5 & 9.2 & 67.1 & 5.1 & 7.7 \\
\hline VCI & 100.8 & 10.3 & 10.2 & 72.7 & 4.2 & 5.8 \\
\hline PRI & 104.2 & 9.6 & 9.2 & 72.6 & 5.8 & 8.0 \\
\hline WMI & 101.8 & 8.6 & 8.4 & 66.3 & 5.3 & 8.0 \\
\hline PSI & 105.5 & 9.4 & 8.9 & 71.4 & 3.9 & 5.4 \\
\hline
\end{tabular}

the negative correlation found between facial emotional recognition and cognitive ability suggests that the development of perceptual abilities interferes with emotional recognition, but it is not the only factor that influences performance, suggesting that other processes (e.g., the influence of emotional character in recognition) are more evident in some emotions than in others. According to Carvajal, Fernández-Alcaraz, Rueda, and Sarrión (2012), the population with DS has distinct neural pathways for processing facial configurations and recognizing emotions. Distinguishing between faces is easier than distinguishing between facial expressions. It is also easier for people with DS to obtain higher scores in tasks in which facial expressions are selected from a category of words in comparison to tasks that require matching informed emotions to pictures of facial expressions.
The comparisons of the correlations between the WISC-III subtests and TEPEF's facial expressions indicated opposite responses in the two groups. In two subtests (Mazes and Arithmetic), one IQ (Verbal IQ), and one factorial index (VCI), the respective correlations with the expression of sadness were negative in the TDC group (Table 5). However, for children with DS, the corresponding correlations were positive (Table 6). Moreover, other moderate positive correlations were found between the expression of sadness and the Picture completion, Vocabulary, and Digits and WMI factorial index in the participants with DS (Table 6). The Picture completion subtest requires visual memory ability. The Vocabulary subtest is related to verbal function and language ability (verbal expression), and the Digits subtest assesses the ability to store information in the 
short term (Lezak et al., 2004). The WMI is composed of the Digits and Arithmetic subtests (arithmetical reasoning).

Considering the expression of anger, emphasizing the differences found between the TDC group and DS group is important. In the TDC group, moderate negative correlations were found between the expression of anger and five WISC-III parameters: Arithmetic, Vocabulary, Comprehension, Verbal IQ, and Total IQ (Table 5). Negative correlations, from moderate to high, were found between the expression of anger and 11 WISC-III parameters in the DS group: Picture arrangement, Arithmetic, Block design, Vocabulary, Object assembly, Comprehension, Verbal IQ, Execution IQ, Total IQ, VCI, and PRI (Table 6). Picture arrangement (perceptual analysis), Block design (organization and visuospatial processing), and Object assembly (perceptual integration) comprise a set of subtests of Execution IQ. Arithmetic (arithmetic reasoning), Vocabulary (expressive language ability), and Comprehension (verbal reasoning) are components of the set to determine Verbal IQ. The VCI is composed of Vocabulary, Comprehension, Information, and Mazes, and the PRI is composed of Picture arrangement, Picture completion, Block design, and Object assembly. When analyzing the subtests that presented a negative correlation with anger, we found that they assess very different abilities, including language abilities, communication, and visual perception. Such data suggest an alteration in general intellectual competence.

When comparing the scores obtained by the two groups on the subtests of WISC-III (Table 7) based on the coefficient of variation (variability of accuracy), we found that the TDC group was above average with less variability. The DS group had lower performance on each subtest and greater variability compared with the TDC group. A specific pattern of performance was not found in the DS group, which was confirmed by the greater variability of hits per subtest, which makes the construction of a profile that justifies the performance in recognizing facial emotions difficult.

Rojahn, Esbensen, and Hoch (2006) stated that the processing of emotions and deficits in social abilities are highly correlated. As suggested by Carvajal et al. (2012), more research is necessary for a better comprehension of how emotional faces are understood by people with DS, similar to other populations with moderate intellectual deficits. Investments in research to establish a cognitive base for the recognition of facial emotions using, for example, neuropsychological assessments or fMRI would be helpful to better understand and delineate cognitive differences between the recognition of different emotions.

Thus, the hypothesis of lower performance in the recognition of facial emotions by the DS group was confirmed. However, the hypothesis of standard cognitive performance that sustains the recognition of facial emotions or lack thereof was not confirmed.

\section{Conclusions}

In the present study, we investigated the perception of facial emotional expressions in children with DS using TEPEF software and searched for correlations with cognitive abilities using WISC-III. Our results suggest the need for more research to stimulate the perception, recognition, and identification of facial emotional expressions in individuals with DS, either in early phases of development or older ages.

Other considerations involve the application of these findings to the clinic and interactions between professionals, families, and friends and individuals with DS. The face is an important instrument of communication that acts as a mediator in social interactions between individuals. Thus, this study contributes to the understanding of the characteristics of recognition of facial emotions by children with DS, an important ability of social mediation with their peers, schools, and families. Professionals and family members who are involved in the care of these individuals must be aware of these difficulties in recognizing facial emotions, stimulate the development of this skill, and use other resources (e.g., speech content, prosody, and body language) to aid communication.

\section{Acknowledgements}

The first author received a scholarship from CAPES. We would like to thank the assistance given by the Secretary of Education of the Federal District and individuals who participated in this study. We would also like to thank Rafael Galvão de Santana, Adriana Manso Melchiades, and Hélida Arrais Costa for their critical analysis of previous versions of this paper. We thank Roberta Ladislau Leonardo for allowing the use of TEPEF. We also thank Prof. Gerson Américo Janczura for advice on statistical analysis.

\section{References}

Argyle, M. (1983). The psychology of interpersonal behaviour, 4th ed. Harmondsworth: Penguin.

Benda, C. E. (1971). Mongolism. In: J. Minckler (Ed.), Pathology of the nervous system (pp. 1361-1371). New York: McGraw-Hill.

Benton, A. L., Sivan, A. B., Hamsher, K. S., Varney, N. R., \& Spreen, O. (1983). Benton Facial Recognition Test. New York: Oxford University Press.

Carvajal, F., Fernández-Alcaraz, C., Ruéda, M., \& Sarrión, L. (2012). Processing of facial expressions of emotions by adults with Down syndrome and moderate intellectual disability. Research in Developmental Disabilities, 33, 783-790.

Cebula, K. R., Moore, D. G., \& Wishart, J. G. (2010). Social cognition in children with Down's syndrome: challenges to research and theory building. Journal of Intellectual Disability Research, 54, 113-134.

Chapman, R. S., \& Hesketh, L. J. (2000). Behavioral phenotype of individuals with Down syndrome. Mental Retardation and Developmental Disabilities Research Reviews, 6, 84-95.

Clark, U. S., Neargarder, S., \& Cronin-Golomb, A. (2008). Specific impairments in the recognition of emotional facial expressions in Parkinson's disease. Neuropsychologia, 46, 2300-2309.

Darwin, C. (1872). The expression of the emotions in man and animals. London: John Murray. 
De Souza, W. C., Feitosa, M. A. G., Eifuku, S., Tamura, \& Ono, T. (2008). Face perception in its neurobiological and social context. Psychology \& Neuroscience, 1(1), 15-20.

Down, J. L. H. (1866). Observations on an ethnic classification of idiots. London Hospital Clinical Lectures and Reports, 3, 259-262.

Ekman, P. (1972). Universals and cultural differences in facial expression of emotion. In: J.K. Cole (Ed.), Nebraska symposium on motivation (pp. 207-283). Lincoln: University of Nebraska Press.

Ekman, P. (1993). Facial expression and emotion. American Psychologist, 48, 384-492.

Ekman, P., \& Friesen, W. V. (1976). Pictures of facial affect. Palo Alto: Consulting Psychologists Press.

Ekman, P., Friesen, W. V., O’Sullivan, M., Chan, A., DiacoyanniTarlatzis, I., Heider, K., Krause, R., LeCompte, W. A., Pitcairn, T., Ricci-Bitti, P. E., Scherer, K., Tomita, M., \& Tzavaras, A. (1987). Universals and cultural differences in judgments of facial expression of emotion. Journal of Personality and Social Psychology, 53, 712-717.

Hippolyte, L., Barisnikov, K., \& Van der Linden, M. (2008). Face processing and facial emotion recognition in adults with Down syndrome. American Journal on Mental Retardation, 11, 292-306.

Hippolyte, L., Barisnikov, K., Van der Linden, M., \& Detraux, J. J. (2009). From facial emotional recognition abilities to emotional attribution: a study in Down Syndrome. Research in Developmental Disabilities, 30, 1007-1022.

Jernigan, T. L., Bellugi, U., Sowell, E., Doherty, S., \& Hesselink, J. R. (1993). Cerebral morphological distinctions between Williams and Down syndromes. Archives of Neurology, 50, 186-191.

Kasari, C., Freeman, S. F. N., \& Hughes, M. A. (2001). Emotion recognition by children with Down Syndrome. American Journal of Mental Retardation, 106, 59-72.

Ladislau, R. L. (2010). Percepção de expressões faciais emocionais em idosos com doença de Alzheimer. Dissertação de Mestrado. Universidade de Brasília. Brasília. Distrito Federal. Brasil.

Lejeune, J., Gautier, M., \& Turpin, R. (1959). Etude des chromosomes somatiques de neuf enfants mongoliens. Comptes Rendus des Séances de l'Académie des Sciences, 248, 1721-1722.

Lezak, M. D., Howieson, D. B., \& Loring, D. W. (2004). Neuropsychological assessment, 4th ed. Oxford: Oxford University Press.

Martínez, G. E. M., \& Ramírez, E. O. L. (2005). Mecanismos cognitivos de reconocimiento de información emocional facial en personas com síndrome de Down. Revista Médica Internacional sobre El Sindrome de Down, 9, 2-6.

Matsumoto, D., \& Hwang, H. S. (2011). Judgments of facial expressions of emotions in profile. Emotion, 11, 1223-1229.

Mundy, P., Kasari, C., Sigman, M., \& Ruskin, E. (1995). Nonverbal communication and early language acquisition in children with Down syndrome and in normally developing children. Journal of Speech and Hearing Research, 38, 157-167.
Mundy, P., Sigman, M., Kasari, C., \& Yirmiya, N. (1988). Nonverbal communication skills in Down syndrome children. Children Development, 59, 235-249.

Pessoa, L. (2008). On the relationship between emotion and cognition. Nature Reviews Neuroscience, 9, 148-158.

Porter, M., Coltheart, M., \& Langdon, R. (2007). The neuropsychological basis of hypersociability in Williams and Down syndrome. Neuropsychologia, 45, 2839-2849.

Raz, N., Torres, I., Briggs, S. D., Spencer, W. D., Thornton, A. E., Loken, W. J., Gunning, F. M., McQuain, J. D., Driesen, N. R., \& Acker, J. D. (1995). Selective neuroanatomical abnormalities in Down's syndrome and their cognitive correlates: evidence from MRI morphometry. Neurology, 45, 356-366.

Roizen, N. J., \& Patterson, D. (2003). Down's syndrome. Lancet, 361, 1281-1289.

Rojahn, J., Esbensen, A. J., \& Hoch, T. A. (2006). Relationships between facial discrimination and social adjustment in mental retardation. American Journal of Mental Retardation, 111, 366-377.

Simões, M. R. (2002). Utilizações da WISC-III na Avaliação Neuropsicológica de crianças e adolescentes. Paidéia, 12, 113-132.

Smith, L., \& von Tetzchner, S. (1986). Communicative, sensorimotor, and language skills of young children with Down syndrome. American Journal of Mental Deficiences, 91, 57-66.

Smith, M. C., \& Dodson, D. G. (1996). Facial expression in adults with Down's syndrome. Journal of Abnormal Psychology, 105, 602-608.

Tristão, R. M., \& Feitosa, M. A. G. (1998). Linguagem na Síndrome de Down. Psicologia: Teoria e Pesquisa, 14, 127-137.

Tristão, R. M., \& Feitosa, M. A. G. (2002). Use of the visual habituation paradigm to investigate speech perception in Down Syndrome infants. In: Eighteenth Annual Meeting of the International Society for Psychophysics: Fechner Day (vol. 28, pp. 552-557). Rio de Janeiro: Legis Summa.

Wechsler, D. (1990). Wechsler Preschool and Primary Scales of Intelligence. London: Psychological Corporation.

Wechsler, D. (1992). Wechsler Intelligence Scales for Children: WISC-III. London: Psychological Corporation.

Wechsler, D. (2002): Escala de Inteligência Wechsler para Crianças WISC-III. São Paulo: Casa do Psicólogo.

Williams, K. R., Wishart, J. G., Pitcairn, T. K., \& Willis, D. S. (2005). Emotion recognition by children with Down syndrome: investigation of specific impairments and error patterns. American Journal on Mental Retardation, 110, 378-392.

Wishart, J. G., \& Pitcairn, T. K. (2000). Recognition of identity and expression in faces by children with Down syndrome. American Journal on Mental Retardation, 105, 466-479.

Wishart, J. G., Cebula, K. R., Willis, D. S., \& Pitcairn, T. K. (2007). Understanding of facial expressions of emotion by children with intellectual disabilities of differing aetiology. Journal of Intellectual Disability Research, 51, 551-563. 